\title{
Information flow within the West African innovation systems
}

\author{
Eustache Mêgnigbêto ${ }^{1,2}$
}

\author{
Correspondence: \\ eustachem@gmail.com \\ ${ }^{1}$ Bureau d'Etudes et de Recherches \\ en Science de l'information (BERSI), \\ 09 BP 477, Saint Michel, Cotonou, \\ Republic of Benin \\ ${ }^{2}$ University of Antwerp, Institute for \\ Education and Information Sciences, \\ IBW, Venusstraat 35, B-2000 \\ Antwerp, Belgium
}

\begin{abstract}
We used mutual information and transmission power as indicators of knowledge circulation between innovation actors. The units of analysis in scientific publications are indexed in the Web of Science with at least one West African-based address. We found that at the regional level, the university is the biggest knowledge producer followed by the government and industry in that order; however, at the national level, the government is the biggest information producer in majority of countries. The industrial sector output is weak both at the regional level and individual country level. It is even null in some countries. Mutual information indicated the existence of synergy between the three actors, both at the regional and national levels. However, its value is too low to allow for knowledge circulating fluently among actors.
\end{abstract}

Keywords: Triple Helix; Innovation system; Research collaboration; Knowledge circulation; West Africa

\section{Multilingual abstracts}

Please see Additional file 1 for translation of the abstract into the five official working languages of the United Nations and Portuguese.

\section{Background}

The role of the university, industry and government has been changing for recent decades. The university does not only teach and do research but also can compete with firms as well, for example, as far as call for tends, bids or services are concerned. The government does not only set up rules, watch over their respect and collect taxes and fund but can also institute administrative body to do research or participate to firm capital. The industry does not only output services, processes and products for the community but also can conduct research for their improvement. Each sector is taking the role of another (Etzkowitz and Leydesdorff 2000; Leydesdorff and Etzkowitz 2001). Etzkowitz and Leydesdorff (1995) elaborated, on this basis, the Triple Helix concept that represents the necessary dynamics among the three sectors. If research activities exploit existing knowledge and produce new ones, knowledge circulation between the university and industry ensures its transformation into innovation. Innovation takes an important place in industrial development, economic growth and wealth production. There is a positive correlation between the levels of research and development activities, the level of absorptive capacity and the pool of knowledge that can be

(c) 2014 Mêgnigbêto; licensee Springer. This is an Open Access article distributed under the terms of the Creative Commons Attribution License (http://creativecommons.org/licenses/by/4.0), which permits unrestricted use, distribution, and reproduction in any medium, provided the original work is properly cited. 
exploited (Mueller 2006). Hence, knowledge flow between actors can indicate a society's level of development and the self-organization.

The Oslo Manual (OECD 2005) defines innovation as 'the implementation of a new or significantly improved product (good or service), or process, a new marketing method, or a new organisational method in business practices, workplace organisation or external relations.' In other words, innovation supposes new things, new ways of doing, creativity and added value. In the Triple Helix model, innovation results from interactions between the three main actors: university, industry and government (Etzkowitz and Leydesdorff 1995, 2000). Research and innovation can be measured, collaboration for research and innovation too (OECD 2005, 2010; Şerbănică 2011). Leydesdorff (2003) introduces mutual information as an indicator of the Triple Helix of relations between the university, industry and government, based on the notion of entropy (Shannon 1948), and Mêgnigbêto (2014b) proposed transmission power as the efficiency of the mutual information. Mutual information indicates the synergy or information flow between innovation actors and transmission power and the strength of information flow within a system or between its actors. Transmission power may help in measuring the level of synergy, the pressure or the control exerted within the system.

West Africa, one of the five African regions as determined by the African Union ${ }^{\mathrm{a}}$, counts 15 countries (listed alphabetically as follows: Benin, Burkina Faso, Cote d'Ivoire, Cape Verde, Gambia, Ghana, Guinea, Guinea-Bissau, Liberia, Mali, Nigeria, Niger, Senegal, Sierra Leone and Togo). All the West African countries are together members of the Economic Community of West African States (ECOWAS), a regional economic integration organization. In early 2012, the region adopted the ECOWAS Policy on Science and Technology (ECOPOST) that recognized the role of science, technology and innovation in regional integration and life condition improvement. From their independence in the early 1960s to the end of the Cold War (end of 1980s), African States and hence almost all the ECOWAS Members States were ruled by single-party authoritarian regimes with central control and a state monopoly in all sectors of the economy. The fall of the Berlin Wall in 1989 had changed the deal at the international level, and most of the developing countries were forced to switch over to democracy with a liberalized political and economic system. West Africa integration institutions and Member States have recognized democracy as a system that sustains peace, stability, economic growth, social and economic development and a condition to regional integration (ECOWAS Commission 2011) and committed to 'deepen and strengthen the democratic institutions using appropriate international standards' with an 'ECOWAS of people' as target.

The Triple Helix of the university-industry-government relationships ensures the knowledge flow among the three sectors and contributes to economic growth and hence to social and economic development. Through innovation and the renewal of the political economy and social structure, the Triple Helix is the key to knowledge-based economic development (Leydesdorff and Etzkowitz 2001) because knowledge creation, flows and capitalization are also important elements in stimulating economic development and contributes to regional growth (Mueller 2006). The aim of this paper is to measure knowledge flow between innovation actors in the West African region. Our research question is how does information circulate among innovation actors in West Africa? For this purpose, we use mutual information and transmission power as indicators. 


\section{Literature review}

Knowledge exploitation requires it to flow (Mueller 2006). Şerbănică (2011) gave an overview of knowledge circulation indicators; she distinguished funding flow (in the form of grants, donations and contracts), cooperation, strategic partnerships, co-publications and patent statistics. Research collaboration understood as co-authorship entails the tacit transfer of information and knowledge (Olmeda-Gómez et al. 2008); it has become an indicator for scientific collaboration measuring and is widely used in academia (Katz and Martin 1997; Bordons and Gomez 2000; Olmeda-Gómez et al. 2008; Abbassi et al. 2012). Several publications studied co-authorship worldwide (e.g. Bordons and Gomez 2000; Adams 2012; Adams et al. 2014) or in Africa (e.g. Tijssen 2007; Boshoff 2009; Adams et al. 2010; Boshoff 2010; Onyancha and Maluleka 2011; Toivanen and Ponomariov 2011; Mêgnigbêto 2013a; Adams et al. 2014). They all reported an increasing trend in the number of authors who contributed to an article; some of them underlined the concentration of the growth in the group of papers with five or more authors, lending strong importance to collaboration. Globally, co-authorship has exploded recently (Adams 2012), and internationalization of collaboration characterizes science today (Adams 2013) .

A number of studies used citation analysis (e.g. Onyancha and Maluleka 2011; Toivanen and Ponomariov 2011; Ponomariov and Toivanen 2014) or economic data (Mueller 2006) to measure knowledge transfer; however, they did neither distinguish the three actors university, industry and government nor used information theory. Some other studies (Leydesdorff 1991, 2003; Leydesdorff and Sun 2009; Park and Leydesdorff 2010; Khan and Park 2011; Ye et al. 2013) focused on the university, government and industry collaboration using information theory, especially mutual information, but they concentrated on European and Asian countries only. Particularly for Africa, university-industrygovernment relationships were dealt with by, e.g. Nwagwu (2008) for Nigeria, Taylor (2004) for South Africa, Mêgnigbêto (2013b) for West Africa and Etzkowitz and Dzisah (2007) for the whole Africa; in 2012, the Association of African Universities conducted a survey on university-industry linkages in Africa in order to determine what interface structures, policies, positions, incentives and funding avenues are currently in place (or lacking) and what services or interventions African institutions themselves gauge to be most important for strengthening their efforts (Ssebuwufu et al. 2012). The above studies on Africa described and analysed relationships between the university, industry and government; in addition, Mêgnigbêto (2013b) discussed the information flow between the Triple Helix actors in West Africa, but he based his study only on mutual information which is not suitable for comparison (Mêgnigbêto 2014b). So, how does transmission power measures information circulation among West African innovation?

\section{Results}

\section{Sectorial outputs and collaboration data}

The university produced $82.82 \%$ of papers, government $41.09 \%$ and industry $1.07 \%$. Research institutions that do not fall under the above categories include NGOs, national or international associations; they account for $3.80 \%$. If data are restricted to West African-based institutions, university produces $67.45 \%$ of papers, industry $0.52 \%$ and government $31.69 \%$; not classified institutions' share rises to $11.46 \%$. The breakdown of records with West African-based addresses per year and Triple Helix actor alongside with their combinations is given in Table 1. Annual data show the same trend and 
Table 1 West African scientific output (number of publications) per Triple Helix actor (2001 to 2010)

\begin{tabular}{ccccccccc}
\hline & U & I & G & UI & UG & IG & UIG & Total \\
\hline 2001 & 780 & 3 & 447 & 1 & 103 & 1 & 0 & 1,335 \\
2002 & 884 & 6 & 454 & 0 & 129 & 1 & 0 & 1,474 \\
2003 & 925 & 8 & 482 & 3 & 156 & 1 & 0 & 1,575 \\
2004 & 1,011 & 4 & 463 & 2 & 151 & 0 & 0 & 1,631 \\
2005 & 1,410 & 6 & 657 & 3 & 252 & 1 & 0 & 2,329 \\
2006 & 1,507 & 6 & 644 & 4 & 238 & 0 & 2 & 2,401 \\
2007 & 2,086 & 7 & 735 & 7 & 327 & 1 & 0 & 3,163 \\
2008 & 2,356 & 10 & 747 & 13 & 400 & 4 & 3 & 3,533 \\
2009 & 2,756 & 7 & 739 & 11 & 427 & 1 & 1 & 3,942 \\
2010 & 2,684 & 12 & 926 & 12 & 497 & 2 & 2 & 4,135 \\
Total & 16,399 & 69 & 6,294 & 56 & 2,680 & 12 & 8 & 25,518 \\
\hline
\end{tabular}

confirm university $(\mathrm{U})$ as the biggest science producer. Due to the effect of the Boolean operator AND, the university and government (UG) produce jointly more than the university and industry (UI) on the one hand and the industry and government (IG) on the other hand; the double Boolean operator makes the joint output of the three sector (UIG) smaller. These results confirm the findings of (Khan and Park 2011). At national levels however (Table 2), the government is the biggest information producer, ahead university and industry in 12 countries; even some countries (Benin, The Gambia, Guinea-Bissau, Liberia, Mali and Niger) have no industrial output. Globally, the industrial sector's output is weak both at the regional and national levels, which indicates that the sector did not use to do research in West Africa.

\section{Knowledge flow between actors}

We used mutual information (Leydesdorff 2003), efficiency and transmission power (Mêgnigbêto 2014b) as measurements of knowledge circulation among the Triple Helix

Table 2 University, industry and government's scientific production (numbers of papers) and relations per West African country (2001 to 2010)

\begin{tabular}{lcccccccc}
\hline Country & Total & U & I & G & UI & UG & IG & UIG \\
\hline Benin & 1,335 & 548 & 0 & 668 & 0 & 93 & 0 & 0 \\
Burkina Faso & 1,785 & 484 & 1 & 1,114 & 0 & 164 & 0 & 0 \\
Cape Verde & 52 & 14 & 3 & 26 & 0 & 1 & 0 & 0 \\
Cote d'Ivoire & 1,669 & 784 & 1 & 808 & 0 & 144 & 0 & 0 \\
Gambia & 986 & 7 & 0 & 208 & 0 & 5 & 0 & 0 \\
Ghana & 3,203 & 1,821 & 30 & 1,371 & 7 & 393 & 5 & 0 \\
Guinea & 241 & 49 & 3 & 168 & 0 & 11 & 0 & 0 \\
Guinea Bissau & 225 & 16 & 0 & 185 & 0 & 13 & 0 & 0 \\
Liberia & 49 & 14 & 0 & 26 & 0 & 4 & 0 & 0 \\
Mali & 1,204 & 517 & 0 & 569 & 0 & 85 & 0 & 0 \\
Niger & 586 & 196 & 0 & 304 & 0 & 16 & 0 & 0 \\
Nigeria & 15,569 & 13,669 & 101 & 2,683 & 53 & 1,339 & 14 & 7 \\
Senegal & 2,544 & 1,062 & 3 & 1,172 & 0 & 180 & 0 & 0 \\
Sierra Leone & 117 & 48 & 2 & 60 & 0 & 8 & 0 & 0 \\
Togo & 433 & 225 & 1 & 191 & 0 & 26 & 0 & 0 \\
\hline
\end{tabular}


Table 3 Mutual information, efficiency and transmission power in the West African regional innovation system (2001 to 2010)

\begin{tabular}{ccccccccccc}
\hline Year & $\boldsymbol{H}_{\mathrm{UI}}$ & $\boldsymbol{H}_{\mathrm{UG}}$ & $\boldsymbol{H}_{\mathbf{I G}}$ & $\boldsymbol{T}_{\mathrm{UI}}$ & $\boldsymbol{T}_{\mathrm{UG}}$ & $\boldsymbol{T}_{\mathbf{I G}}$ & $\boldsymbol{H}_{\text {UIG }}$ & $\boldsymbol{T}_{\text {UIG }}$ & $\boldsymbol{\eta}(\%)$ & $\boldsymbol{\tau}(\%)$ \\
\hline 2001 & 955.865 & $1,286.049$ & $1,012.942$ & 2.442 & 614.59 & 0.555 & $1,302.003$ & -16.631 & 46.38 & 2.62 \\
2002 & 931.816 & $1,305.719$ & $1,011.11$ & 8.00 & 559.293 & 1.064 & $1,312.687$ & -27.457 & 46.76 & 4.61 \\
2003 & 955.245 & $1,341.708$ & $1,035.819$ & 4.492 & 527.666 & 2.93 & $1,366.786$ & -32.054 & 48.69 & 5.65 \\
2004 & 897.325 & $1,281.585$ & 988.034 & 1.65 & 537.846 & 2.513 & $1,294.369$ & -18.098 & 46.11 & 3.23 \\
2005 & 899.961 & $1,321.885$ & $1,003.876$ & 2.292 & 505.689 & 1.336 & $1,339.818$ & -18.384 & 47.73 & 3.48 \\
2006 & 887.04 & $1,283.405$ & 993.949 & 0.856 & 508.355 & 0.714 & $1,307.019$ & -20.216 & 46.56 & 3.81 \\
2007 & 828.477 & $1,241.652$ & 963.006 & 1.422 & 465.821 & 1.442 & $1,266.507$ & -15.719 & 45.11 & 3.24 \\
2008 & 820.374 & $1,242.741$ & 981.809 & 1.917 & 420.384 & 0.259 & $1,293.071$ & -18.110 & 46.06 & 4.11 \\
2009 & 745.523 & $1,175.459$ & 921.863 & 0.872 & 401.677 & 0.829 & $1,207.097$ & -12.637 & 43.00 & 3.04 \\
2010 & 830.119 & $1,278.736$ & 987.123 & 1.738 & 424.206 & 1.029 & $1,315.113$ & -19.390 & 46.85 & 4.34 \\
Total & 859.781 & $1,271.635$ & 985.837 & 1.778 & 475.607 & 0.966 & $1,300.798$ & -18.652 & 46.34 & 3.75 \\
\hline
\end{tabular}

Entropies and transmissions in millibits of information.

actors. The unit of analysis is publications. The regional university-industry-government system data are output in Table 3. The entropy $\left(H_{\mathrm{UIG}}\right)$ ranges from 1.207 bits in 2009 to its highest value (1.367 bits) in 2003; no trend is depicted over the period (Figure 1). It comes that from 2001 to 2010, the West African innovation system produced less than half its capacity; indeed, annual efficiencies $(\eta)$ are lower than one half, ranging from $43 \%$ to $48 \%$. Annual transmissions ( $\left.T_{\mathrm{UIG}}\right)$ are negative indicating synergy among actors; in other words, the system is not centrally controlled over the studied period of times. However, the interactions between actors are too low and cannot ensure better knowledge circulation. Indeed, transmission varies from -13 to -32 millibits, and, consequently, transmission power $(\tau)$ ranges from 0.026 to 0.057 meaning that $3 \%$ to $6 \%$ of the system's information sharing capacity was really used. In other words, much information does not circulate among innovation actors in West Africa. Synchronous data (Table 3, row total) reveals that the West African innovation system products 1.301 bits of information representing $46 \%$ of its capacity; the synergy is evaluated to -19 millibits that is $4 \%$ of the information sharing capacity.

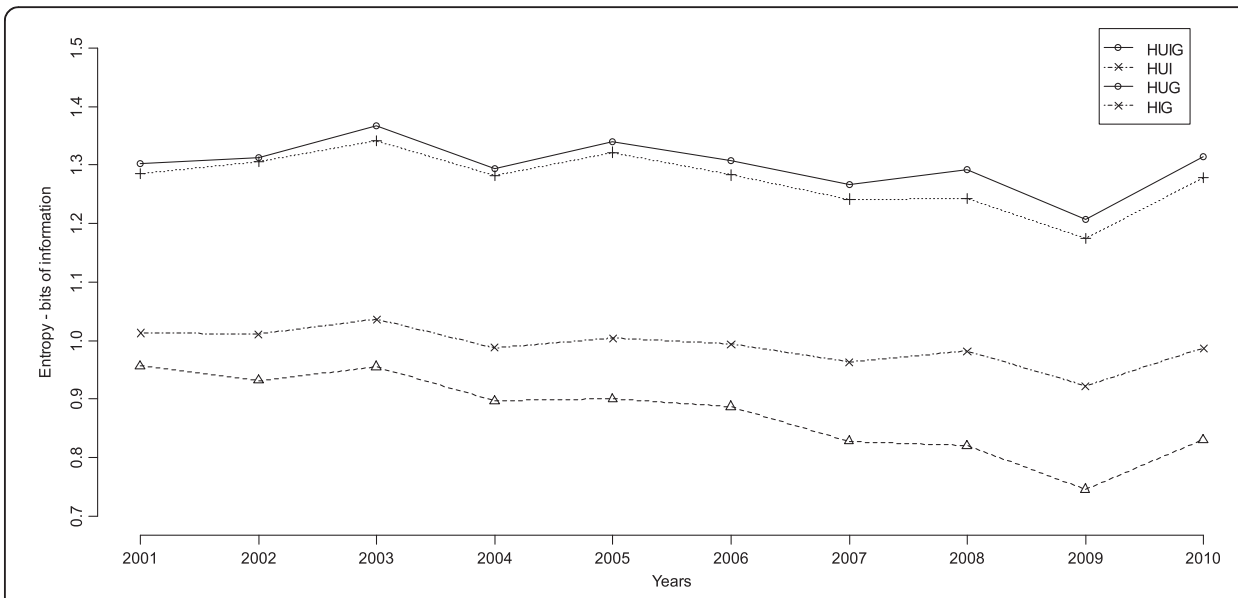

Figure 1 Relative positions of $H_{U I}, H_{U G}, H_{I G}$ and $H_{U I G}$ (2001 to 2010). 
The comparison of bilateral transmissions $\left(T_{\mathrm{UI}}, T_{\mathrm{UG}}\right.$ and $\left.T_{\mathrm{IG}}\right)$ reveals that whatever the year is, the entropy of the university-government system $\left(H_{\mathrm{UG}}\right)$ is higher than that of the university-industry system $\left(H_{\mathrm{UI}}\right)$ which in turn is higher than that of the industrygovernment system $\left(H_{\mathrm{IG}}\right)$; the system's entropy $\left(H_{\mathrm{UIG}}\right)$ is the highest (Figure 1$)$.

Entropy measures uncertainty; when the transmission $\left(T_{\mathrm{UIG}}\right)$ is negative, it contributes to the reduction of the uncertainty that prevails at the system level (Leydesdorff 2003). In Equation 6, the right term groups entropies, thus positive values; however, bilateral entropies are affected with the negative sign. Therefore, the higher they are, the more negative the transmission. In other words, bilateral entropies contribute to the reduction of the uncertainty at the system level. In the case of the West African innovation system, $H_{\mathrm{UG}}>H_{\mathrm{UI}}>H_{\mathrm{IG}}$ over 2001 to 2010 (Figure 2); we conclude that at the tri-lateral system level, the university-government relations contribute more to the uncertainty reduction than the other two bilateral systems.

At national levels, because industrial output is null in some countries, $H_{\mathrm{UI}}$ and $H_{\mathrm{U}}$ on the one hand and $H_{\mathrm{IG}}$ and $H_{\mathrm{G}}$ on the other hand are equal; therefore, the transmission between the industrial sector and the two others are null as far as these countries are concerned. In the remaining countries, $T_{\mathrm{UI}}$ and $T_{\mathrm{IG}}$ are weak (0.1 to 10 millibits). Whatever the country is, $H_{\mathrm{UG}}$ is greater than $H_{\mathrm{UI}}$ and $H_{\mathrm{IG}}$, and $T_{\mathrm{UG}}$ than $T_{\mathrm{UI}}$ and $T_{\mathrm{IG}}$. The national system with the highest entropy is the Sierra Leonean ( $H_{\mathrm{UIG}}=1.387$ bits), and the one with the lowest value is the Gambian $\left(H_{\mathrm{UIG}}=0.359 \mathrm{bits}\right)$. Cape Verde has the highest transmission $\left(T_{\mathrm{UIG}}=-217\right.$ millibits), and the six countries with 0 output for industrial sector has a null transmission. The Gambia has however the less efficient system $(\eta=13 \%)$ and Ghana the most efficient one $(\eta=55 \%)$. Out of the nine countries with a non-null transmission, Cape Verde has the highest transmission power $\left(\tau=\tau_{1}=0.245\right)$ and Burkina Faso the lowest $\left(\tau=\tau_{1}=0.010\right)$. These data suggest that the amount of knowledge that circulates among actors is larger in Cape Verde than elsewhere in West Africa, and that the Cape Verdean innovation system shares more information among its actors than elsewhere.

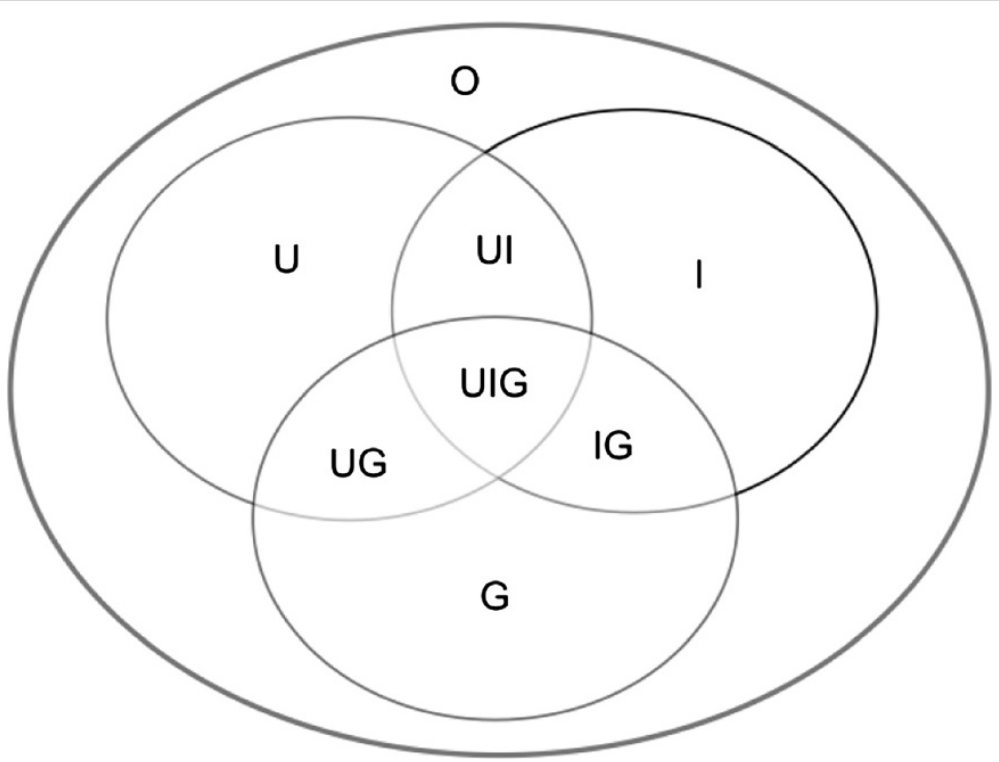

Figure 2 Cardinalities in a tri-dimensional system $S=(U, I, G)$. 


\section{Discussion}

Among the 15 West African Member States, 6 has no industrial output; over the remaining, 2 (Ghana and Nigeria) exhibit relationships between the industry and government on the one hand and the industry and university on the other hand, but the joint collaboration between the three actors occurs only in Nigeria. This results show that there is no tradition in industrial research in the region. Indeed, the West African industrial sector is facing a number of problems that make less than half its capacity is really used (ECOWAS Commission 2010; Mêgnigbêto 2013b). The numerous untapped underground and mineral resources the region is endowed with are exported rather than processed locally (ECOWAS Commission 2010), so final products are mainly conceived out of Africa and not for African. Consequently, the local industry does not need research activities to improve products, processes or services.

In the countries with null industrial output, the bilateral transmissions $T_{\mathrm{UI}}$ and $T_{\mathrm{IG}}$ are null; further, the trilateral transmission $T_{\mathrm{UIG}}$ is null. These results suggest that regarding research output, there is no knowledge transfer between the industrial sector and the two others on the one hand and there is no information transfer between the three actors on the other hand. Only Nigeria and Ghana show industrial collaboration with the university $(\mathrm{U})$ and government $(\mathrm{G})$ sectors, but Ghana has no universityindustry-government (UIG) relations; these two countries have the higher industrial contribution to gross domestic product (GDP). On its own, Nigeria counts one half the region industries and contributed 40\% of the regional GDP in 2006 (ECOWAS Commission 2010), that means industrial activities are better developed in this country than elsewhere in West Africa.

It is expected that the university is ranked first with respect to scientific output, because of the flow of doctoral students and scholars' publishing activities. At the national level, except Ghana, Nigeria and Togo, the university output is lower than the governmental one, certainly because the hospital, which is also the affiliation of some scholars, is categorized into the governmental body. However, Nigeria on its own produces half the regional output (Mêgnigbêto 2013c, d, e, 2014), and its university share is the largest compared with other countries; consequently, the regional output is balanced in favour of the university. The ranking of countries with respect to transmission and transmission power yields the same result, leaving at the rear the six countries with null industrial output ${ }^{\mathrm{e}}$. In comparison with other countries, taking into account a 10-year period (Mêgnigbêto 2014b), West Africa performs less than individual countries like the USA, the UK, Germany, France, Russia, India, Brazil and Korea for their 1-year data. Indeed, these countries' transmission and transmission power for the year 2001 are respectively -0.074 bits and $0.229,-0.063$ bits and $0.211,-0.043$ bits and $0.186,-0.052$ bits and $0.184,-0.024$ bits and $0.093,-0.078$ bits and $0.169,-0.022$ bits and 0.099 , and -0.253 bits and 0.286 . The synergy among innovation actors over a 10-year period in West Africa based on scientific publications is less than that of these countries over 1 year.

One may notice that for countries with no industrial output, and thus no collaboration between the industry and other sectors $(\mathrm{I}=\mathrm{UI}=\mathrm{IG}=\mathrm{UIG}=0)$, the trilateral transmission $\left(T_{\mathrm{UIG}}\right)$ is null, while not all bilateral transmissions $\left(T_{\mathrm{UI}}, T_{\mathrm{UG}}\right.$ and $\left.T_{\mathrm{IG}}\right)$ are null. In bilateral relations, transmission measures the level of independence between variables (cf. (Batina et al. 2011). That is, if two variables are independent, the transmission between them is 
null. If more than two random variables are mutually independent, there are also pairwise independent (Yeung 2001, 2008; Cover and Thomas 2006). In a tri-dimensional system, if the system's transmission is null, therefore, the variable are mutually independent, so there are pairwise independent (cf. (Yeung 2001, 2008; Cover and Thomas 2006). However, our results show that in some cases, the tri-dimensional transmission is null, whereas not all bilateral transmissions are null. According to Leydesdorff (2014a), this happens because mutual information in three or more dimensions is not a Shannon-type information; there are loops involved that may generate redundancies (Leydesdorff and Ivanova 2014; Leydesdorff 2014b). Interactions with loops entail positive or negative redundancies (Krippendorff 2009a). Krippendorff (2014) claims that this is a proof that algebra is not able to get unique interactions among three or more variables for the simple reason that probabilities do not take care of circular interactions which begin with three or more variables (Krippendorff 2009a, 2009b).

Another remark is that except the two countries with UI and IG relations (Ghana and Nigeria, in italics in Table 4) where $H_{\mathrm{UG}}$ is less than $H_{\mathrm{UIG}}, H_{\mathrm{UIG}}$ equals $H_{\mathrm{UG}}$ elsewhere. This result suggests that the trilateral university-industry-government system operates like a simple bilateral university-government one. Therefore, one may expect $T_{\mathrm{UIG}}$ to be positive as in the case of a bi-dimensional system and $T_{\mathrm{UI}}$ equal to $T_{\mathrm{UG}}$, as if the presence of industrial output or relations with the university or government had no effect, but calculations give $T_{\mathrm{UIG}} \leq 0$. Leydesdorff and Ivanova (2014) gave an explanation:

A spurious correlation can reduce uncertainty, as when two parents reduce uncertainty for a child by providing mutually consistent answers to questions. (...). The marriage can be considered as a latent construct in which the child plays a role without constituting it. Similarly, in university-industry-government relations, a strong existing relation between two of the partners can make a difference for the third.

Table 4 Mutual information, entropies, efficiency and transmission power in the West African national innovation system (2001 to 2010)

\begin{tabular}{lcccccccccc}
\hline Country & $\boldsymbol{H}_{\mathbf{U I}}$ & $\boldsymbol{H}_{\mathbf{U G}}$ & $\boldsymbol{H}_{\mathbf{I G}}$ & $\boldsymbol{T}_{\mathbf{U I}}$ & $\boldsymbol{T}_{\mathbf{U G}}$ & $\boldsymbol{T}_{\mathbf{I G}}$ & $\boldsymbol{H}_{\mathbf{U I G}}$ & $\boldsymbol{T}_{\mathbf{U I G}}$ & $\boldsymbol{\eta}(\%)$ & $\boldsymbol{\tau}(\%)$ \\
\hline Benin & 999.693 & $1,292.234$ & 980.815 & 0.00 & 688.274 & 0.00 & $1,292.234$ & 0.00 & 46.03 & 0.00 \\
Burkina Faso & 955.336 & $1,255.31$ & 958.565 & 0.375 & 542.153 & 1.057 & $1,255.310$ & -5.503 & 44.72 & 1.00 \\
Cape Verde & $1,241.939$ & $1,362.402$ & $1,222.163$ & 42.849 & 525.696 & 99.351 & $1,362.402$ & -216.902 & 48.53 & 24.51 \\
Cote d'Ivoire & $1,003.003$ & $1,335.648$ & 999.688 & 0.635 & 654.285 & 0.66 & $1,335.648$ & -5.731 & 47.58 & 0.87 \\
Gambia & 305.401 & 358.848 & 203.43 & 0.00 & 149.982 & 0.00 & 358.848 & 0.00 & 12.78 & 0.00 \\
Ghana & $1,047.245$ & 143.309 & $1,085.431$ & 7.114 & 529.522 & 5.228 & $1,464.74$ & -47.321 & 52.18 & 8.03 \\
Guinea & 920.677 & $1,099.2$ & 841.019 & 5.678 & 496.54 & 28.368 & $1,099.2$ & -65.955 & 39.15 & 11.06 \\
Guinea Bissau & 572.369 & 706.835 & 383.464 & 0.00 & 248.998 & 0.00 & 706.835 & 0.00 & 25.18 & 0.00 \\
Liberia & 976.021 & $1,288.65$ & 902.393 & 0.00 & 589.764 & 0.00 & $1,288.65$ & 0.00 & 45.9 & 0.00 \\
Mali & 999.427 & $1,301.385$ & 990.104 & 0.00 & 688.146 & 0.00 & $1,301.385$ & 0.00 & 46.36 & 0.00 \\
Niger & 976.946 & $1,135.453$ & 957.932 & 0.00 & 799.336 & 0.00 & $1,135.543$ & 0.00 & 40.45 & 0.00 \\
Nigeria & 696.48 & $1,027.455$ & 850.4 & 9.091 & 370.181 & 0.53 & $1,066.119$ & -31.148 & 37.98 & 7.58 \\
Senegal & $1,011.925$ & $1,318.699$ & $1,002.108$ & 1.293 & 670.551 & 1.469 & $1,318.688$ & -11.011 & 46.97 & 1.61 \\
Sierra Leone & $1,106.157$ & $1,386.951$ & $1,085.815$ & 15.927 & 594.332 & 21.284 & $1,386.951$ & -86.739 & 49.4 & 12.08 \\
Togo & $1,007.537$ & $1,279.648$ & $1,020.604$ & 2.728 & 707.221 & 2.195 & $1,279.648$ & -18.175 & 45.58 & 2.49 \\
\hline
\end{tabular}

Entropies and transmissions in millibits of information. 


\section{Conclusions}

This paper uses publications as unit of analysis and computes the collaboration between the university, industry and government from data collected at the international level for 15 West African countries. We used mutual information and transmission power as indicators of knowledge flow. We computed indicators both for the region and individual countries. We found that at the regional level, the university is the biggest knowledge producer followed by the government and industry in that order; however, at the national level, the government is the biggest information producer in majority of countries. The industrial sector output is weak both at the regional level and individual country level. It is even null in some countries.

Mutual information indicated the existence of synergy between the three actors, both at the regional and national levels. However, its value is too low to allow for knowledge circulating fluently among actors. Consequently, annual transmission power which indicates the efficiency of mutual information has weak values at the regional level. This indicator shows large variation at the national level, ranging from 0 in six countries to $25 \%$ in Cape Verde.

\section{Methods}

\section{Data collection}

The elaboration of the Triple Helix thesis lays on the collaboration between the university, industry and government. Of course, collaboration may cover several aspects and not all collaboration yields publications. In this paper, however, we focus on research collaboration understood as co-authorship. We downloaded West African scientific publication data from Thomson Reuters' Web of Science over a 10-year period (2001 to 2010). The databases selected were Science Citation Index Expanded (SCI-EXPANDED), Conference Proceedings Citation Index-Science (CPCI-S), Conference Proceedings Citation Index- Social Science \& Humanities (CPCI-SSH) and Index Chemicus (IC). The search expression was $c u=$ benin or $c u=$ cote ivoire or $c u=$ niger or $c u=$ senegal or $c u=$ cape verde or $c u=$ gambia or $c u=$ ghana or $c u=n i g e r i a$ or $c u=$ togo or $c u=$ mali or $c u=l i b e r i a$ or cu=sierra leone or $c u=$ guinea or $c u=$ burkina faso or $c u=$ guinea-bissau. The 28,380 resulting records were downloaded and imported into a bibliographic database managed with the CDS/ISIS ${ }^{c}$ software application. Based on Leydesdorff's (2003) method for label assignment to addresses, we coded a Pascal CDS/ISIS ${ }^{\mathrm{d}}$ programme that assigned each address the label 'university' (abbreviated UNIV), 'industry' (abbreviated INDU) or 'government' (abbreviated GOV) to each address. A record may contain many addresses; therefore, one record may have two or more different labels. The CDS/ISIS programme was also instructed to read the countries' name from the addresses and automatically add the associated two characters ISO codes to the label. Non-West African countries were given unique identifiers ZZ. Therefore, in the inverted file, a university in Benin appears under the label UNIV-BJ, and an enterprise in a non-West African country appears under ZZ-INDU.

The CDS/ISIS search function operates mainly over the inverted file that contains 'searchable terms' as previously defined by the database administrator upon a field. It admits the Boolean operators OR symbolized by the sign + (plus), AND symbolized by the character * (star) and NOT symbolized by the character ${ }^{\wedge}$ (circumflex). We run 
searches over the CDS/ISIS database using keywords composed of each country names and Triple Helix actors' codes. For example, the search expressions (1) to (7) were conducted for Benin:

(1)UNIV-BJ: retrieves all records the university in Benin authored;

(2) INDU-BJ: retrieves all records the industry in Benin authored;

(3)GOV-BJ: retrieves all records the government in Benin authored;

(4) UNIV-BJ * INDU-BJ retrieves all records the university and industry in Benin co-authored;

(5) UNIV-BJ * GOV-BJ retrieves all records the university and industry in Benin co-authored;

(6) INDU-BJ * GOV-BJ retrieves all records the industry and government in Benin co-authored;

(7) UNIV-BJ * INDU-BJ * GOV-BJ retrieves all records the university, industry and government in Benin co-authored;

Finally, the contribution of each actor was computed as follows (according to the Venn diagram in Figure 2):

$\mathrm{U}=(1)-(4)-(5)+(7)$ : number of publications university only authored;

$\mathrm{I}=(2)-(4)-(6)+(7)$ : number of publications industry only authored;

$\mathrm{G}=(3)-(5)-(6)+(7)$ : number of publications government only authored;

$\mathrm{UI}=(4)-(7)$ : number of publications university and industry only co-authored;

UG = (5) - (7): number of publications university and government only co-authored;

$I G=(6)-(7)$ : number of publications industry and government only co-authored;

UIG = (7): number of publications university, industry and government co-authored.

Such searches and computation were run for individual countries and then for the whole region.

\section{Entropy, mutual information, efficiency and transmission power}

Shannon (1948) defined the entropy of an event that occurs with the probability $p$ as

$$
H=-p \times \log _{2} p-(1-p) \times \log _{2}(1-p)
$$

where $\log _{2}$ is the logarithm to the base 2; the entropy may however be computed to other bases, e.g. $3,4, \ldots, 10$. More generally, if $X=\left(x_{1}, x_{2}, \ldots, x_{n}\right)$ is a random variable and its components occur with the probabilities $p_{1}, p_{2}, \ldots, p_{n}$, respectively, then the entropy generated by $X$ is (Shannon 1948; Shannon and Weaver 1949)

$$
H_{X}=-\sum_{i=1}^{n} p_{i} \times \log _{2} p_{i}
$$

An information source is a random variable that produces symbols (Shannon 1948; Cover and Thomas 2006; Mori 2006; Le Boudec et al. 2013). An information source may also be composed of two or more random variables. For two random variables $X$ and $Y$ (two dimensions), if $H_{X}$ is the entropy of $X$ and $H_{Y}$ that of $Y$, the joint entropy $H_{X Y}$ of the two variables is equal to the entropy $H_{X}$ plus $H_{Y}$ 
minus the entropy of the overlay of $X$ and $Y$. The latter is called 'rate of transmission' (Shannon 1948) or mutual information (Yeung 2001, 2008; Leydesdorff 2003; Cover and Thomas 2006; Mori 2006) between $X$ and $Y$. The relations between the transmission, $T_{X Y}$, the joint entropy, $H_{X Y}$, and the marginal entropies of the variables, $H_{X}$ and $H_{Y}$, are (Shannon 1948)

$$
H_{X Y}=H_{X}+H_{Y}-T_{X Y}
$$

and

$$
T_{X Y}=H_{X}+H_{Y}-H_{X Y}
$$

In case of three random variables $X, Y$ and $Z$ (three dimensions), Leydesdorff (2003) and Leydesdorff and Ivanova (2014), citing McGill (1954), Theil (1972) and Abramson (1963), demonstrated that the relations between the system's entropy, its transmission, the marginal entropies and the bilateral transmissions are given by

$$
H_{X Y Z}=H_{X}+H_{Y}+H_{Z}-T_{X Y}-T_{X Z}-T_{Y Z}+T_{X Y Z}
$$

and

$$
T_{X Y Z}=H_{X}+H_{Y}+H_{Z}-H_{X Y}-H_{Y Z}-H_{X Z}+H_{X Y Z}
$$

Transmission or mutual information may be used as innovation indicator. According to Leydesdorff (2003), in more than two dimensions, if the transmission is negative, it indicates the level of synergy or information flow between variables; if it is positive, it indicates how centrally controlled is the system. A null transmission means an absence of interactions between variables. However, Krippendorff (2009a, b) claims that mutual information does not measure the unique interactions in a complex system and a null transmission could not be interpreted as the absence of interaction within a system.

Mêgnigbêto (2014b) defined the efficiency of a system as the fraction of its information production capacity that is really produced, relative unused capacity is the complement to 1 of the efficiency, and the transmission power of a system is the fraction of the maximum value of the transmission devoted to information sharing in the system. It represents the share of the 'total configurational information' really produced in the system. In other words, it measures the efficiency of the mutual information. All the three indicators vary from 0 to 1 ; they all are dimensionless and may be expressed as percentage.

In a tri-dimensional one, two types of transmission power are distinguished (Mêgnigbêto 2014b): the first one $\left(\tau_{1}\right)$ when the transmission is negative and the second $\left(\tau_{2}\right)$ when the transmission is positive:

$$
\tau=\left\{\begin{array}{r}
\tau_{1}=\frac{T_{X Y Z}}{H_{X Y Z}-H_{X}-H_{Y}-H_{Z}} \text { if } T_{X Y Z}<0 \\
\tau_{2}=\frac{T_{X Y Z}}{H_{X Y Z}} \text { if } T_{X Y Z}>0 \\
0 \text { if } T_{X Y Z}=0
\end{array}\right.
$$

\section{Endnotes}

${ }^{a}$ Resolution CM/Res.464 (XXVI) adopted by the African Unity Organization (now African Union) Council of Ministers meeting in its Twenty-sixth Ordinary Session in 
Addis-Ababa (Ethiopia) from 23 February to 1 March 1976. The countries' list was updated in 2004.

${ }^{\mathrm{b}}$ Adams (2013) said that international collaboration is the fourth age of science after the individual, the institutional and the national level.

${ }^{\mathrm{c}} \mathrm{CDS}$-ISIS is a text database management software developed and distributed by UNESCO (1989a).

${ }^{\mathrm{d}} \mathrm{CDS} / \mathrm{ISIS}$ provides a programming language 'designed to develop CDS/ISIS applications requiring functions which are not readily available in the standard package' (UNESCO 1989b). This programming language enables users to extend functions of the standard package, to make it more robust and in order to meet users' specific needs (Mêgnigbêto 1998).

${ }^{\mathrm{e}}$ The list in decreasing order of mutual information or transmission power is as follows: Cape Verde, Sierra Leone, Guinea, Ghana, Nigeria, Togo, Senegal, Burkina Faso, Cote d'Ivoire, Benin, The Gambia, Guinea Bissau, Liberia, Mali and Niger.

\section{Additional file}

Additional file 1: Multilingual abstracts in the five official working languages of the United Nations and Portuguese.

\section{Competing interests}

The author declares that he has no competing interests.

\section{Acknowledgements}

This article is an extended version of a short paper published in ISSI Newsletter (Mêgnigbêto 2014a).

Received: 11 March 2014 Accepted: 30 June 2014

Published online: 24 October 2014

\section{References}

Abbassi A, Liaquat $H$, Leydesdorff $L$ (2012) Betweeness centrality as a driver of preferential attachment in the evolution of research collaboration networks. J Informetr 6:403-412

Abramson N (1963) Information theory and coding. McGraw-Hill, New York

Adams J (2012) Collaborations: the rise of research networks. Nature 490:335-336. doi:10.1038/490335a

Adams J (2013) The fourth age of research. Nature 497:557-560. doi:10.1038/490335a

Adams J, King C, Hook D (2010) Global research report: Africa. Thomson Reuters, New York

Adams J, Gurney K, Hook D, Leydesdorff L (2014) International collaboration clusters in Africa. Scientometrics 98:547-556. doi:10.1007/s11192-013-1060-2

Batina L, Gierlichs B, Prouff E, Rivain M, Standaert F-X, Veyrat-Charvillon N (2011) Mutual information analysis: a comprehensive study. J Cryptol 24:269-291. doi:10.1007/s00145-010-9084-8

Bordons M, Gomez I (2000) Collaboration networks in science. In: Cronin B, Atkins HB (ed) Web of knowledge: a festschrift in honor of Eugene Garfield. Information Today, Medford, pp 197-213

Boshoff N (2009) Neo-colonialism and research collaboration in Central Africa. Scientometrics 81:413-434

Boshoff N (2010) South-South research collaboration of countries in the Southern African Development Community (SADC). Scientometrics 84:416-434

Cover TM, Thomas JA (2006) Elements of information theory, 2nd edition. Wiley, Hoboken

ECOWAS Commission (2010) West African Common Industrial Policy (WACIP). ECOWAS Commission, Abuja

ECOWAS Commission (2011) ECOWAS vision 2020: towards a democratic and prosperous community. ECOWAS Commission, Abuja

Etzkowitz H, Dzisah J (2007) The Triple Helix of innovation: towards a university-led development strategy for Africa. ATDF J 4:3-10

Etzkowitz H, Leydesdorff L (1995) The Triple Helix —university-industry-government relations: a laboratory for knowledge-based economic development. EEASST Rev 14:14-19

Etzkowitz H, Leydesdorff L (2000) The dynamics of innovation: from National Systems and "Mode 2" to a Triple Helix of university-industry-government relations. Res Policy 29:109-123

Katz JS, Martin BR (1997) What is research collaboration? Res Policy 26:1-26

Khan FG, Park HW (2011) Measuring the Triple Helix on the Web: longitudinal trends in the university-industry-government relationship in Korea. J Am Soc Inf Sci 62:2443-2455

Krippendorff K (2009a) Information of interactions in complex systems. Int J Gen Syst 38:669-680

Krippendorff K (2009b) Ross Ashby's information theory: a bit of history, some solutions to problems, and what we face today. Int J Gen Syst 38:189-212 
Krippendorff K (2014) Re: variables independence and mutual information. Cybern. Discuss. Group CYBCOM. https://hermes.gwu.edu/cgibin/wa?A2=ind1401\&L=cybcom\& $F=\& S=\& P=23173$

Le Boudec J-Y, Thiran P, Urbanke R (2013) Sciences de l'information

Leydesdorff L (1991) The static and dynamic analysis of network data using information theory. Soc Netw 13:301-345

Leydesdorff L (2003) The mutual information of university-industry-government relations: an indicator of the Triple Helix dynamics. Scientometrics 58:445-467

Leydesdorff L (2014a) Re: variables independence and mutual information. Cybern. Discuss. Group CYBCOM. https://hermes.gwu.edu/cgibin/wa?A2=ind1401\&L=cybcom\&F=\&S=\&P=23043

Leydesdorff L (2014b) Re: variables independence and mutual information. Cybern. Discuss. Group CYBCOM. https://hermes.gwu.edu/cgibin/wa?A2=ind 1402\&L=cybcom\&F=\&S=\&P=22491

Leydesdorff L, Etzkowitz H (2001) The transformation of university-industry-government relations. Electron J Sociol 5

Leydesdorff L, Ivanova IA (2014) Mutual redundancies in interhuman communication systems: steps towards a calculus of processing meaning. J Assoc Inf Sci Technol 65:386-399. doi:10.1002/asi.22973

Leydesdorff L, Sun Y (2009) National and international dimensions of the Triple Helix in Japan: university-industry-government versus international co-authorship relations. J Am Soc Inf Sci 60:778-788

McGill WJ (1954) Multivariate information transmission. Psychometrika 19:97-116

Mêgnigbêto E (1998) Le traitement des particules nobiliaires: une expérience avec CDS/SIS. Doc-Sci L'information 35:321-325

Mêgnigbêto E (2013a) Scientific publishing in West Africa: comparing Benin with Ghana and Senegal. Scientometrics 95:1113-1139. doi:10.1007/s11192-012-0948-6

Mêgnigbêto E (2013b) Triple Helix of university-industry-government relationships in West Africa. J Scientometr Res 2(3):54-62

Mêgnigbêto E (2013c) International collaboration in scientific publishing: the case of West Africa (2001-2010). Scientometrics 96:761-783. doi:10.1007/s11192-013-0963-2

Mêgnigbêto E (2013d) Scientific research in West Africa: a global view (2001-2010). ISSI Newletter 9:6-11

Mêgnigbêto E (2013e) Scientific publishing in West Africa: a comparison with BRICS. In: Hinze S, Lottmann A (ed) Transl. Twists Turns Sci. Scio-Econ. Endeav. Proc. STI 2013. Institute for Research Information and Quality Assurance - European Network of Indicators Designers, Berlin, pp 557-560

Mêgnigbêto E (2014a) Information flow between West African Triple Helix actors. ISSI Newsl 10:14-20

Mêgnigbêto E (2014b) Efficiency, unused capacity and transmission power as indicators of the Triple Helix of universityindustry-government relationships. J Informetr 8:284-294. doi:http://dx.doi.org/10.1016/j.joi.2013.12.009

Mori Y (2006) Electronique pour le traitement du signal. Théorie de l'information et du codage: signal analogique, signal numérique et applications en télécommunications. Lavoisier, Paris

Mueller P (2006) Exploring the knowledge filter: how entrepreneurship and university-industry relationships drive economic growth. Res Policy 35:1499-1508. doi:10.1016/j.respol.2006.09.023

Nwagwu WE (2008) The Nigerian university and the triple helix model of innovation systems: adjusting the wellhead. Technol Anal Strateg Manag 20:683-696. doi:10.1080/09537320802426374

OECD (2005) Oslo Manual: guidelines for collecting and interpreting innovation data, 3rd edition. Organisation for Economic Co-operation and Development - Statistical Office of the European Communities, Paris

OECD (2010) Measuring innovation: a new perspective. OECD, Paris

Olmeda-Gómez C, Perianes-Rodríguez A, Antonia Ovalle-Perandones MA (2008) Comparative analysis of university-government-enterprise co-authorship networks in three scientific domains in the region of Madrid. Inf Res 13

Onyancha OB, Maluleka JR (2011) Knowledge production through collaborative research in sub-Saharan Africa: how much do countries contribute to each other's knowledge output and citation impact? Scientometrics 87(2):315-336

Park HW, Leydesdorff L (2010) Longitudinal trends in networks of university-industry-government relations in South Korea: the role of programmatic incentives. Res Policy 2009:640-649

Ponomariov B, Toivanen H (2014) Knowledge flows and bases in emerging economy innovation systems: Brazilian research 2005-2009. Res Policy 43:588-596. doi:10.1016/j.respol.2013.09.002

Serbănică C (2011) Knowledge circulation between universities, public research organizations and business in the EU 27. Drivers, barriers, actions to be put forward. Eur J Interdiscip Stud 3:43-54

Shannon CE (1948) A mathematical theory of communication. Bell Syst Tech J 27:379-423. and 623-656

Shannon CE, Weaver W (1949) The mathematical theory of communication. University of Illinois, Urbana

Ssebuwufu J, Ludwick T, Béland M (2012) Strenghening university-industry linkages in Africa: a study on institutional capacities and gaps. Association of African Universities - Association of Universities and Colleges of Canada, Accra

Taylor S (2004) Knowledge circulation: the "triple helix" concept applied in South Africa. Ind High Educ 18:329-334

Theil H (1972) Statistical décomposition analysis. North-Holland, Amsterdam

Tijssen RJW (2007) Africa's contribution to the worldwide research literature: new analytical perspectives, trends and performance indicators. Scientometrics 71:303-327

Toivanen H, Ponomariov B (2011) African regional innovations systems: bibliometric analysis of research collaboration patterns 2005-2009. Scientometrics 88:471-493

UNESCO (1989a) Mini-micro CDS/ISIS: manuel de référence: version 2.3. UNESCO, Paris

UNESCO (1989b) Mini-micro CDS/ISIS: Pascal CDS/ISIS. UNESCO, Paris

Ye YF, Yu SS, Leydesdorff L (2013) The Triple Helix of university-industry-government relations at the country level, and its dynamic evolution under the pressures of globalization. J Am Soc Inf Sci Technol 64:2317-2325

Yeung RW (2001) A first course in information theory. Kluwer, Boston

Yeung RW (2008) Information theory and network coding. Springer

doi:10.1186/s40604-014-0005-y

Cite this article as: Mêgnigbêto: Information flow within the West African innovation systems. Triple Helix 2014 1:5. 